\title{
O ENREDO DAS AULAS EXPERIMENTAIS NO ENSINO FUNDAMENTAL: CONCEPÇÕES DE PROFESSORES SOBRE ATIVIDADES PRÁTICAS NO ENSINO DE CIÊNCIAS
}

\author{
THE STORYLINE OF EXPERIMENTAL LESSONS IN ELEMENTARY SCHOOL: \\ TEACHERS' CONCEPTIONS OF PRACTICAL ACTIVITIES IN SCIENCE \\ TEACHING
}

DOI: http://dx.doi.org/10.23926/RPD.2526-2149.2020.v5.n1.p271-288.id606

\author{
Maria Eliane Oliveira \\ da Silva \\ Graduada em Licenciatura \\ em Ciências Naturais \\ (UFMA) \\ Professora da Educação \\ Básica (SEMED/CODÓ) \\ elianed_oliver@hotmail.com \\ .br
}

\section{Paulo Roberto Brasil de Oliveira Marques \\ Doutor em Química \\ (UNESP) \\ Professor na Universidade \\ Federal do Maranhão \\ (UFMA). \\ paulo.brasil@ufma.br}

\section{Clara Virgínia Vieira Carvalho Oliveira Marques \\ Doutora m Ciências/Ensino \\ de Química pela \\ Universidade Federal de São \\ Carlos (UFSCar) \\ Professora na Universidade \\ Federal do Maranhão \\ (UFMA) \\ clarabrasi110@gmail.com}

Resumo: A literatura especializada vem apontando mudanças no ensino de ciências e exprime a experimentação como uma alternativa para o processo de construção de saberes científicos por meio da reflexão e investigação. No contexto nacional, o cenário escolar mantém práticas pedagógicas ainda resistentes às mudanças relacionadas a alfabetização científica mediadas por práticas experimentais. Assim, a presente pesquisa objetivou investigar a concepção de professores de ciências sobre de implementação de práticas experimentais em escolas da rede pública de Ensino Fundamental. Com base nos aspectos metodológicos de uma abordagem qualitativa, os dados foram tratados por análise de conteúdo e organizados na perspectiva de uma rede sistêmica. Os resultados obtidos revelaram que os professores de ciências compreendem a importância da utilização da experimentação para construção de saberes científicos, porém, os planejamentos escolares não contemplam a inserção efetiva dessas atividades, tendo como principais fatores a falta de recursos e espaço próprio destinado à prática experimental.

Palavras-chave: Ensino de Ciências; Práticas Experimentais; Professores de Ciências.

\begin{abstract}
The specialized literature has pointed out changes in science education and expresses experimentation as an alternative to the process of building scientific knowledge through reflection and investigation. In the national context, the school scenario maintains pedagogical practices that are still resistant to changes related to scientific literacy mediated by experimental practices. Thus, the present research aimed to investigate the conception of science teachers about the implementation of experimental practices in public elementary schools. Based on the methodological aspects of a qualitative approach, the data were treated by content analysis and organized from the perspective of a systemic network. The results obtained revealed that science teachers understand the importance of using experimentation to build scientific knowledge, however, school planning does not include the effective insertion of these activities, having as main factors the lack of resources and proper space for experimental practice.
\end{abstract}

Keywords: Science Teaching; Experimental Practices; Science Teachers. 


\title{
1 INTRODUÇÃO
}

Tratar sobre ensino de ciências é direcionar-se para uma das áreas do conhecimento que abrange temas extremamente relevantes para a atuação crítica e reflexiva do indivíduo em formação e dependendo da forma de como é trabalhada na escola, tais temas poderão impulsionar à construção de perspectivas para a formação da cidadania. Partindo desse pressuposto, percebe-se pela retórica da literatura que o ensino de ciências vem sendo ao longo dos tempos alvo de várias propostas de transformações metodológicas, com intuito de alcançar um ensino sob premissas problematizadoras, para que os alunos possam aprender conceitos científicos por meio de reflexões e no prisma de aprendizagem mais significativa (JUNIOR; PARREIRA, 2016; TAHA et al., 2006; PRSYBYCIEM; SILVEIRA, SAUER, 2018). Para Santos (2006) o ensino de ciências deve ter por objetivo:

\begin{abstract}
[...] melhorar as condições da formação do espírito científico dos alunos em vista das circunstâncias histórico-culturais da sociedade. Tais alterações tentam situar a ciência e o seu ensino no tempo e no espaço, enfatizando em cada momento um aspecto considerado mais relevante na forma de o homem entender e agir cientificamente no mundo por meio de um conhecimento que, de modo geral, esteja além do senso comum (SANTOS, 2006, p. 1).
\end{abstract}

A Lei de Diretrizes e Bases da Educação Nacional - LDBEN (nº 9.394/96) preconiza que as propostas de implementações do ensino de ciências devam inserir no currículo elementos que busquem acompanhar os avanços do conhecimento científico, valorizando-se a participação ativa do estudante no processo de aprendizagem. Consequentemente, esse ensino deve atender a demanda da sociedade do conhecimento, desenvolvendo no educando posturas diferenciadas para que ele possa atuar de forma consciente, critica e reflexiva. Nessa ótica, é imprescindível a inserção de metodologias de ensino diferentes das que estão em vigor.

Desde os Parâmetros Curriculares Nacionais - PCN (1998) que atuaram na década passada como orientadores do currículo, e a atual Base Nacional Comum Curricular -BNCC (2017) propõe-se que no ensino de ciências se busque:

"[...] favorecer o desenvolvimento de postura reflexiva e investigativa, de não aceitação, a priori de ideias e informações, assim como a percepção dos limites das explicações, inclusive dos modelos científicos, colaborando para a construção da autonomia de pensamento e de ação" (BRASIL, 1998, p.23).

No entanto, apesar de todo esse movimento de reflexões sobre o ensino de ciências, ele continua sendo foco de debates e discussões na literatura especializada, pelo fato de ainda se apresentar estagnado e sem mudanças significativas (DELIZOICOV; ANGOTTI, 2002; GUIMARÃES, 2009; CACHAPUZ et al., 2011; SANTOS, 2006; TRIVELATO; SILVA, 2011, FERRARO, 2017, SILVA, 2019). Para Ferraro (2017) esse fenômeno pode estar relacionado 
diretamente à resistência de mudanças nas estratégias metodológicas de ensino utilizadas em sala de aula, que incidem na dicotomia entre teoria e prática, priorizando memorização de conceitos e fórmulas, desconectados da realidade do estudante.

Nesse contexto, ressalta-se uma das linhas defendidas por pesquisadores no intuito da melhoria do ensino de ciências que é a incorporação efetiva de práticas experimentais nas aulas de ciências a partir da contextualização e interdisciplinaridade, ou seja, experimentação como parte do processo de ensino, visando envolver e motivar a aprendizagem dos alunos por meio de situações reais e cotidianas, constituindo-se, portanto, numa ferramenta para a construção do pensamento científico significativo (ANDRADE e MASSABNI, 2011; ATAIDE e SILVA, 2011; DELIZICOIV e ANGOTTI, 2000; BASSOLI, 2014; PINTO; 2018; SILVA, 2019). Carneiro (2009, p. 1) comenta que "a experimentação pode ser uma estratégia eficiente para a criação de problemas reais que permitam a contextualização e o estímulo de questionamentos de investigação".

Desde Sicca (1996) já havia defesa que a prática investigativa no ensino de ciências possibilita ao educando maior aproximação ao trabalho científico, induzindo-o a uma melhor compreensão dos fenômenos naturais. Nesse mesmo enfoque, Silva e Zanon (2000) consideram que a experimentação tem um papel fundamental no ensino de ciências, por apresentar-se como uma forma de constituir ligações entre a teoria e prática em sala de aula, bem como, as observações que essas atividades possibilitam incidem na qualidade de construção de argumentação dos estudantes.

Dessa forma, o professor apresenta-se como peça fundamental no tocante a implementação de estratégias para mudança da cultura metodológica e do incentivo a prática experimental nas aulas de ciências, uma vez que é o planejamento do professor que oficializa a presença e favorece condições de diálogo entre teoria e prática voltadas para o desenvolvimento do espírito investigativo e para a construção do conhecimento científico (GIORDAN, 1999; GALLIAZZI; GONÇALVES, 2004; CARVALHO e GIL-PEREZ, 2006, SILVA 2019). Porém, sabe-se que para que isso ocorra é necessário a constante aquisição de saberes pedagógicos e científicos que facilitem o processo de mudança na práxis docente e que levem o professor de ciências a visualizar a importância do discurso teórico atrelado ao prático.

Sob essa ótica de discussão, torna-se de suma relevância estudos que busquem caracterizar aspectos sobre a utilização da experimentação na prática docente como estratégia de melhorias na qualidade do processo de ensino e aprendizagem das ciências no Ensino Fundamental. Portanto, a presente pesquisa se propôs a verificar aspectos da efetiva inserção 
da prática experimental no trabalho docente em escolas de Ensino Fundamental, a partir dos seguintes questionamentos: Qual a concepção de professores de ciências sobre aulas experimentais? Existe a cultura de aulas experimentais nessas escolas? Como é o perfil dos experimentos apresentados? Quais experimentos possuem mais destaque ou chamam mais atenção e por quê foram escolhidos para esse contexto escolar?

\section{Percurso metodológico}

Esta pesquisa teve por base os aspectos metodológicos de uma abordagem qualitativa em educação na vertente da experimentação no ensino de ciências, onde conforme salientam Lüdke e André (2015), a pesquisa qualitativa permite que o pesquisador tenha um maior contato com o seu objeto de pesquisa proporcionando um melhor entendimento do fenômeno a ser estudado. Considerando essa abordagem, o presente trabalho foi desenvolvido na zona urbana do município de Codó, interior do estado do Maranhão, envolvendo professores em exercício da disciplina de ciências - segunda etapa do Ensino Fundamental ( $6^{\circ}$ ao $9^{\circ}$ ano), atuantes na rede pública de ensino, dos turnos matutino e vespertino. Salienta-se o processo da pesquisa iniciou-se com visitação à SEMED/Codó e após a autorização via documental concedida por esse órgão, deu-se contato com os professores de ciências em cada escola que compõe a zona urbana da cidade, onde nesse momento foram informados do teor da pesquisa e convidados a participarem voluntariamente. Mediante o aceite de cada um(a), solicitou-se assinatura em um termo de consentimento livre e esclarecido (TCLE).

Na coleta de dados foram utilizados dois instrumentos: um questionário fechado e uma entrevista semiestruturada, ambos aplicados em etapas distintas. Nos questionários, buscou-se obter informações referentes ao objeto de pesquisa, pontualmente em relação aos elementos que configurassem contribuições na aplicação de aulas experimentais. Nesse sentido, considerou-se três aspectos: i) espaço físico/laboratórios, i) disponibilidade de material/kits de ciências iii) incentivo da gestão na realização de prática experimental. Além disso, questionouse, de forma fechada, sobre outros dois fatores que também pudessem influenciar na realização de aulas experimentais: i) conteúdo disciplinar que oferece melhor oportunidade para aulas experimentais ii) segurança de transposição teórica e prática para aplicar aulas experimentais. Quanto às entrevistas, procurou-se obter informações relacionadas aos aspectos ligados a frequência de aplicabilidade dos experimentos, importância, dificuldades encontradas, experimentos de mais destaque e o perfil destas aulas.

Figura 1: 
Figura 1 - Esquema da Rede Sistêmica adaptada de Marques (2010) para análise das entrevistas

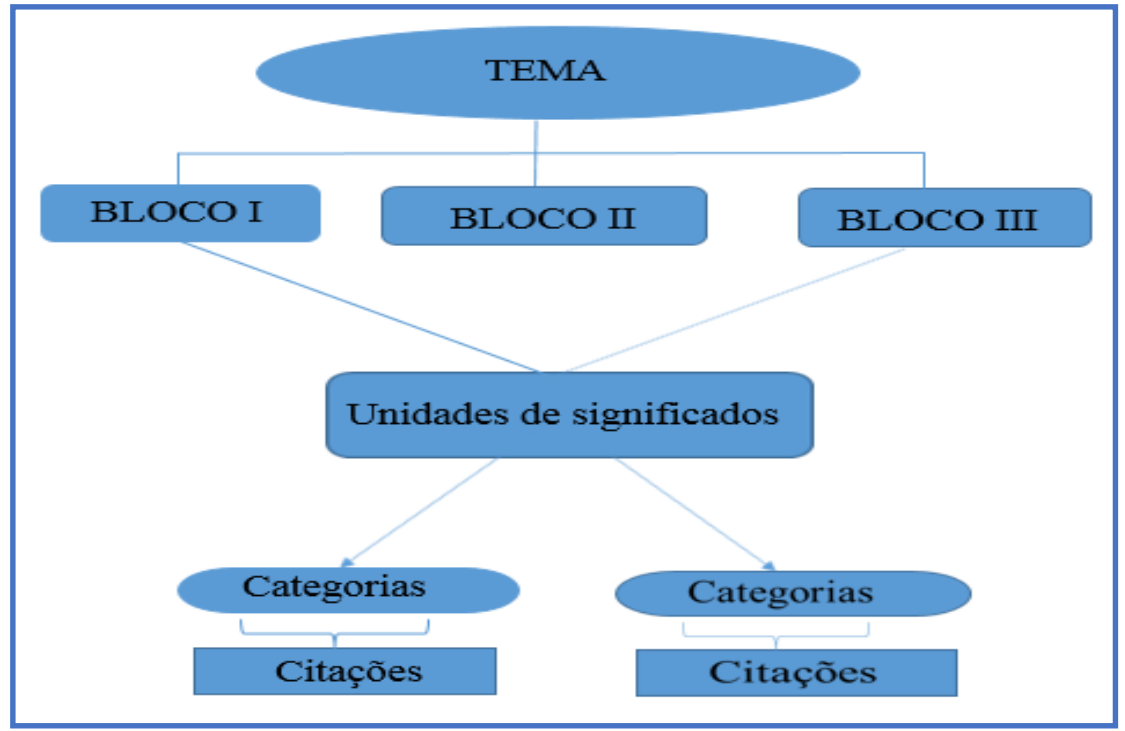

Fonte: próprias autoras, 2019.

Para o tratamento e análise dos dados obtidos nas entrevistas adotou-se a perspectiva de análise de conteúdo com a construção de uma rede sistêmica, conforme mostra o esquema da figura 1 (BARDIN, 2002; MARQUES, 2010). Dessa forma, procedeu-se a identificação de unidades de significados (signos) mais recorrentes nas falas dos entrevistados, com as quais foram sintetizadas em categorizações utilizando o princípio da rede sistêmica, onde em seguida organizou-se em três blocos para análise para então vislumbrar o fenômeno explícito.

Na zona urbana da cidade de Codó/Maranhão, segundo dados do INEP (2017) existem 14 escolas que ofertam o Ensino Fundamental II. Porém, durante a visita in locus constatou-se que 2 dessas escolas não ofertam mais o Ensino Fundamental nas series finais, perfazendo, portanto, um total de 12 escolas como campo de investigação desta pesquisa. Destas, 9 oferecem Ensino Fundamental II nos dois turnos e 3 oferecem em apenas em um dos turnos. Participaram efetivamente da pesquisa professores de apenas 10 escolas, considerando-se que duas instituições se recusaram, por motivos diversos. Em relação aos professores de ciências, o número total deles e delas constituiu-se de 17 pessoas, onde todos foram contatados e convidados a contribuir com a investigação, porém destes, 4 não participaram. Logo, o universo da pesquisa configurou-se com um total de 13 professores, o que equivale a $76,5 \%$ do levantamento inicial. 


\section{ReSUltados E DisCUSSÕES}

\subsection{O CAMPO E OS SUJEITOS DA PESQUISA}

$\mathrm{Na}$ visita in locus verificou-se que das 10 escolas visitadas, 09 não possuem espaço físico destinado às atividades experimentais (90\%). Pelo relato dos professores entrevistados, em 07 escolas existem incentivo para aulas experimentais por parte da gestão escolar e apenas 01 das escolas possui kit de ciências. Esses dados apontam que a prática experimental nas disciplinas de ciências é entendida como necessária pela grande parte da comunidade escolar, porém, urge o cumprimento de atitudes mais precisas para que de fato oportunizem essas atividades acontecerem, incluindo a inserção de instrumentos apropriados para implementação metodológica experimental, que não precisa ser necessariamente de grande porte ou de última tecnologia, mas, que minimamente sejam didáticos e estabeleçam um diálogo coerente com as especificidades necessárias na construção da linguagem cientifica.

Esses pontos destacados nas falas dos professores são comuns em outras pesquisas dentro de instituições escolares, pois segundo Borges (2004), Gonçalves e Marques (2006), Ramos e Rosa (2008), Rosito (2003), Silva, Clemente e Pires (2015) grande parte dos professores da Educação Básica apontam os mesmos problemas encontrados nessa pesquisa, que são: a falta de laboratórios nas escolas, falta de kits básicos para realizar experimentos na própria sala de aula, no caso da inexistência de um laboratório convencional, e por vezes, pouco ou nenhum incentivo da gestão escolar.

\subsection{FATORES PARA VIABILIZAÇÃO DE ATIVIDADES EXPERIMENTAIS}

Quanto aos fatores relativos a influências na realização das atividades experimentais, questionou-se aos professores sobre qual das disciplinas que compõem a área das ciências naturais (Química, Física e Biologia) eles concebem ter "facilidade" para realizar atividades experimentais, bem como foram indagados se eles se sentiam preparados para ministrar práticas experimentais.

Em relação ao primeiro questionamento, os componentes disciplinares que mais facilitam ou oportunizam aulas experimentais se apresentaram na seguinte ordem de citação: 07 consideraram ser a disciplina de Química (54\%), 04 preferem Biologia (30\%) e 02 (15,3\%) professores preferem a disciplina de Física. Dessa forma, os conteúdos de química configuramse como a disciplina mais citada como propícia para atividades experimentais. Esse panorama pode ser explicado pelo fato da tradicional forma de pensar a construção do conhecimento químico atrelado ao espaço de laboratórios e também, dos livros didáticos de química terem 
aumentado, nos últimos anos, o número de opções de atividades experimentais, principalmente no volume do $9^{\circ}$ ano. Em relação às respostas da segunda indagação, as respostas se compilaram da seguinte forma: 09 disseram se sentirem preparados para aplicar aulas experimentais $(69,2 \%)$ e 04 salientam não se sentirem preparados $(30,08 \%)$.

Sabe-se que o perfil da formação específica contemplada nas instituições formadoras em uma grande área não é proporcional ao conjunto de estratégias para aquisição de competências para transposição didática, dessa forma, entende-se que os cursos de formação de professores deveriam direcionar formação profissional para além do saber específico, ou seja, o saber fazer também deveria ter a mesma atenção para o desenvolvimento de formação docente (MARQUES, 2010). Segundo Carvalho e Gil-Perez (2006) o abismo existente entre a importância atribuída à teoria e às atividades práticas na formação inicial de professores de ciências leva exatamente a falta de preparo para implementação dessas atividades na práxis docente, pois muitos deixam de realizar essas práticas por não se considerem capazes diante da realidade que lhes é apresentada, como a falta de suporte técnico e materiais, a superlotação das salas de aulas e principalmente a carência ligada à sua formação. Partindo desse ponto de vista, Agostini e Delizoicov (2000) chamam atenção para a importância de políticas públicas de incentivo à formação docente inicial e continuada com relação às práticas escolares mais reflexivas, incluindo a abordagem sobre a experimentação como instrumento da docência em ciências.

\subsection{ANÁLISE DO CONTEÚDO DAS ENTREVISTAS COM OS PROFESSORES DE CIÊNCIAS}

A análise do conteúdo das entrevistas foi organizada em três blocos de discussões formados por categorização das unidades de significados. Para Strauss; Corbin (2008) o processo de orquestrar conceitos em categorias é fundamental para que o analista reduza a quantidade de unidades com as quais se trabalha, e a partir dos conceitos derivados dos dados poder representar o fenômeno em questão. Assim, uma vez identificados os signos mais recorrentes nos discursos dos entrevistados, compilou-se categorias e suas respectivas subcategorias, organizando-as sob o princípio das redes sistêmicas (MARQUES, 2010). A figura 04 ilustra a rede sistêmica que se deu sob a perspectiva analítica que suscitou os blocos de análise: i) Concepções dos professores sobre suas aulas experimentais; ii) Perfil das aulas experimentais implementadas e iii) Entraves de aplicação das atividades experimentais. 
Figura 2 - Rede Sistêmica sobre o Diagnóstico da Experimentação no Ensino de Ciências

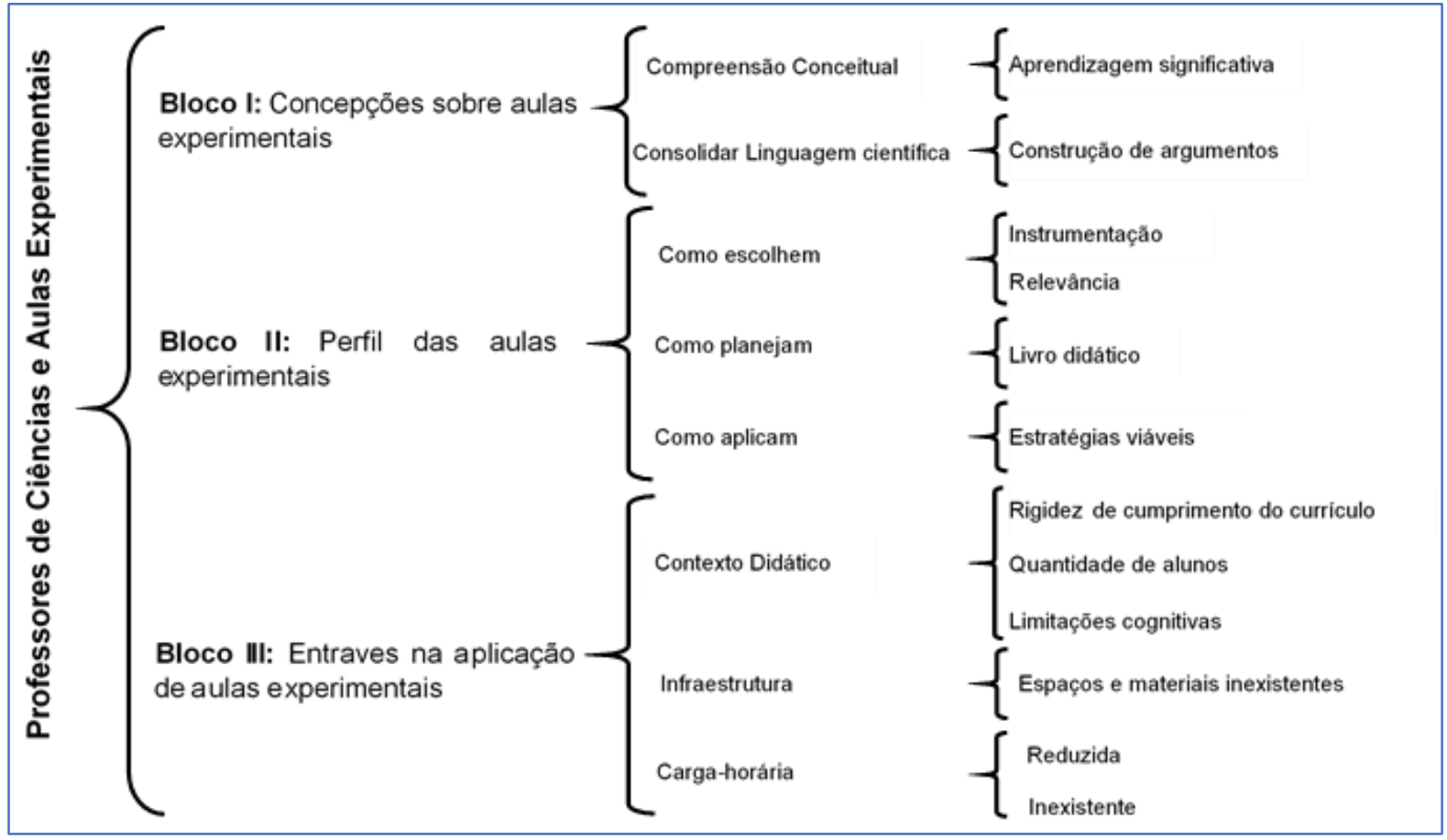

Fonte: Elaborado pelas autoras, 2019

\subsubsection{CONCEPÇões dos Professores SObRe Aulas EXPERIMENTAiS}

De acordo com o que foi exposto pelos sujeitos dessa pesquisa, revelou-se que do grupo total de professores, três deles declararam não aplicar aulas experimentais, pois não concebem esse tipo de procedimento sem espaço físico destinado para essa função, portanto, suas aulas costumam ser somente expositivas. Esses professores não entraram no rol de perguntas subsequentes, porque a pesquisa se destinava a quem implementava aulas experimentas na sua prática docente.

Em relação à definição dada pelos professores que seguiram sendo entrevistados sobre suas concepções a respeito de aulas experimentais, os dados suscitaram duas categorias (Quadro 1), a saber: i) Facilitador para apropriação conceitual e ii) Facilitador para aquisição de postura científica. Na opinião dos professores - Facilitador para apropriação conceitual é entendida como sendo uma estratégia que contribui para consolidar a compreensão e/ou memorização de conceitos por meio da associação entre teoria e da ilustração prática, ou seja, uma forma de confrontar os conceitos científicos vistos em sala de aula, com os vistos em momento de prática. Porém, é importante salientar que o sentido de compreender o conteúdo é bem distinto do ato de memorizar, principalmente quando se quer desenvolver linguagem científica efetiva nos estudantes em formação, a compreensão se torna fator indispensável. Estudos revelam que para que haja aprendizagem de fato, as atividades propostas pelos 
professores devem ser potencialmente significativas, e para tanto os alunos devem estar engajados para além da memorização, em um movimento de querer saber o sentido do que estão vivenciando (COLL, 1994; POZO, 2002; CACHAPUZ et al., 2011).

Já no sentido da segunda categoria - Facilitador para aquisição de postura científica, entendeu-se que um universo prático oportuniza o desenvolvimento de competências para a área científica, que resulta na diferenciação da formação dos alunos em linguagem e argumentação científica no tocante as suas concepções do saber sobre ciências, o que somente pela aula teórica de dentro de sala de aula não poderiam ser construídas.

Dessa forma, pode-se afirmar que os professores reconhecem a importância da experimentação no ensino de ciências, acreditam que a prática permite a assimilação dos conceitos científicos de forma mais significativa, pois além de estabelecer elos entre teoria e prática, também facilita a compreensão e atitudes. Compartilhando dessa mesma concepção Andrade e Massabni (2011) apontam que a experimentação tem um grande potencial em promover uma aprendizagem mais ativa por meio do estímulo ao pensamento crítico, e do desenvolvimento das capacidades de interação, negociação de informações e resolução de problemas, bem como desenvolvimento da capacidade de auto regulação do processo de ensinoaprendizagem, colaborando, portanto, para uma prática mais rica e produtiva.

Quadro 1:.

Quadro 1 - Descrição das unidades de significados do Bloco I

\begin{tabular}{|c|c|c|c|c|}
\hline \multirow{3}{*}{ 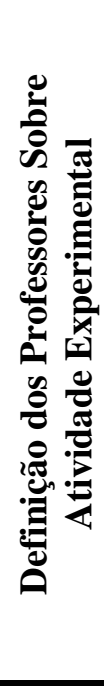 } & Categorias & $\begin{array}{l}\text { Unidades de } \\
\text { Significados }\end{array}$ & Frequência & Citações \\
\hline & $\begin{array}{l}\text { Apropriação } \\
\text { conceitual }\end{array}$ & $\begin{array}{l}\text { Memorizar } \\
\text { conceitos }\end{array}$ & $69,2 \%$ & $\begin{array}{c}\text { P4 “[...] eu vejo como uma forma de } \\
\text { consolidar os conceitos teóricos } \\
\text { P5 "É importante para fixar compreensão } \\
\text { dos conceitos [...]" } \\
\text { P1 “[...] as aulas experimentais são } \\
\text { importantes por que com elas, o aluno } \\
\text { assimila melhor a teoria [...]" }\end{array}$ \\
\hline & $\begin{array}{l}\text { Desenvolvimento } \\
\text { de postura } \\
\text { científica }\end{array}$ & $\begin{array}{l}\text { Consolidar } \\
\text { linguagem } \\
\text { científica }\end{array}$ & $46,2 \%$ & $\begin{array}{c}\text { P3 “[...] quando "gente' coloca a teoria } \\
\text { dentro da sala de aula e também a prática, } \\
\text { o aluno vai perceber e aprender que existe } \\
\text { uma realidade por trás daquilo que se } \\
\text { trabalha teoricamente e ele costuma falar } \\
\text { diferente [...]. }\end{array}$ \\
\hline
\end{tabular}

Fonte: próprias autoras, 2019.

Ressalta-se que a prática da experimentação não deve ser vista unicamente como meio de ligação entre teoria e prática, no sentido de comprovação de conceitos ou como forma de consolidação de conteúdo, pois essas vertentes, a tornariam numa prática resumida a um mero 
ensaio científico, destinado simplesmente à ilustração e/ou comprovação de um determinado fenômeno. A experimentação vai além desses muros, é necessário considerar que através da experimentação, seja possível se fazer novas descobertas, repensar teorias, ou ainda tentar compreender um determinado conteúdo antes da teoria (SILVA, 2019). E como tal, deve possibilitar ao aluno problematizar o conhecimento já teorizado antes, no que se refere ao processo de questionamento reconstrutivo.

Nessa perspectiva, o conteúdo a ser trabalhado caracteriza-se como resposta aos questionamentos feitos pelos educandos durante a interação com o contex to criado, sendo capaz promover maior envolvimento deles, a compreensão de conceitos e a construção de novos conhecimentos favorecendo, portanto, o processo educativo. Assim, entende-se que a maneira como os professores concebem a experimentação tem forte influência no modo de como planejam e executam as atividades experimentais no ensino de Ciência, por isso é imperdível que se tenha uma consciência favorável aos processos de construção do saber cientifico.

\subsubsection{Perfil das aulas EXPERIMENTAis aPlicadas Pelos PROFESSORES}

Neste bloco, buscou-se caracterizar o perfil das aulas experimentais aplicadas pelos professores quanto aos procedimentos de escolhas, planejamento e formas de implementação. O Quadro 2 mostra as categorias formuladas com base nas falas mais recorrentes dos professores entrevistados. A primeira categoria denominada de como escolhem se destinou a revelar como os professores elegem as práticas experimentais a serem implementadas em suas aulas de ciências. Observou-se que dos critérios mencionados os mais utilizados para constituírem o rol dessas aulas, dependem essencialmente dos elementos subcategorizados de: (i) aparato disponível nas escolas $(61,5 \%)$ e; (ii) da relação com o cotidiano dos alunos $(46,2 \%)$.

Segundo TAHA et al. (2016) as atividades experimentais são primordiais para a aprendizagem científica, pois são estratégias eficientes para a criação de problemas reais que permitam a contextualização e o estímulo de questionamentos de investigação. Portanto, entende-se que essas características devem ser levadas em consideração durante a escolha das atividades, e que preferencialmente, transcenda a intenção de demonstrar um conhecimento já estabelecido através da experimentação.

Partindo do pressuposto da experimentação ser essencial para um bom ensino de ciências, considera-se essencial a oferta de materiais nas escolas. Entretanto, deve-se ter o cuidado para que a escassez ou indisponibilidade de materiais não seja fator limitante de proposição de prática de atividades experimentais no ensino de ciências. Nessa perspectiva, as 
atividades com materiais alternativos são apontadas como possibilidade de superar tais dificuldades presentes na maioria das escolas (MACIEL; LIMA, 2011; PINTO, 2018).

A segunda categoria, definida de como planejam, se destinou a verificar como os professores intentam pedagogicamente suas aulas experimentais no plano anual da disciplina, e nessa vertente os professores declararam que programam as aulas seguindo principalmente $\mathrm{o}$ rol de conteúdo do livro didático $(76,92 \%)$ ou por pesquisas em sites da internet (33\%). Destacaram ainda que o modo de aplicação dessas aulas varia de acordo com a possibilidade do momento, podendo ser aplicada antes ou depois da teoria, dependendo da situação de execução do calendário escolar (76,9). Delizoicov e Angotti (2000) comentam que quando bem planejadas, levando em conta os objetivos que se almeja alcançar, a experimentação favorece momentos particularmente ricos no processo de ensino-aprendizagem, para tanto o reconhecimento dos procedimentos essenciais no processo de planejamento, não só das atividades experimentais, mas também de toda prática docente são imprescindíveis.

\begin{tabular}{|c|c|c|c|c|}
\hline \multirow{5}{*}{ 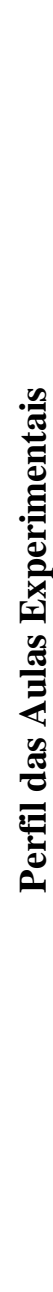 } & Categorias & $\begin{array}{l}\text { Unidades de } \\
\text { Significados }\end{array}$ & Frequência & Citações \\
\hline & \multirow[t]{2}{*}{ Como escolhem } & Instrumentação & $61,5 \%$ & $\begin{array}{c}\text { P1 “[...] primeiramente há aquela seleção } \\
\text { de experimentos [...] que de fato tenha } \\
\text { material [...] procuro fazer experimentos } \\
\text { simples e prático }[\ldots . .] \text { ”. P2 “[...] eu } \\
\text { escolho de acordo com nós podemos fazer, } \\
\text { por que como não temos materiais } \\
\text { disponíveis, as aulas experimentais } \\
\text { acontecem de acordo com a } \\
\text { disponibilidade de material" }\end{array}$ \\
\hline & & Relevância & $46,2 \%$ & $\begin{array}{l}\text { P3 “[...] dentro de cada conteúdo, existem } \\
\text { aqueles que são de essencial importância } \\
\text { para se trabalhar aula prática experimental, } \\
\text { busco fazer alguma coisa." P4 "[...] as } \\
\text { aulas experimentais escolho baseado no } \\
\text { conteúdo [...] ligado ao dia-a-dia [...]". P5 } \\
\text { "[...] sempre procuro uma prática que } \\
\text { aborde mais de um conteúdo." }\end{array}$ \\
\hline & Como planejam & Livro didático & $76,92 \%$ & $\begin{array}{l}\text { P7 “O planejamento segue o livro } \\
\text { didático, então vai conforme o rol de } \\
\text { conteúdo do livro [...]". P8" [...] "A } \\
\text { gente" segue de acordo com a } \\
\text { programação do livro didático. }\end{array}$ \\
\hline & Como aplicam & $\begin{array}{l}\text { Estratégias } \\
\text { viáveis }\end{array}$ & $76,9 \%$ & $\begin{array}{l}\text { P9“[...] depois da aula teórica "a gente" } \\
\text { vai para a prática }[\ldots] " \text {.. P10 “[...] a } \\
\text { aplicação acontece no início ou no final da }\end{array}$ \\
\hline
\end{tabular}




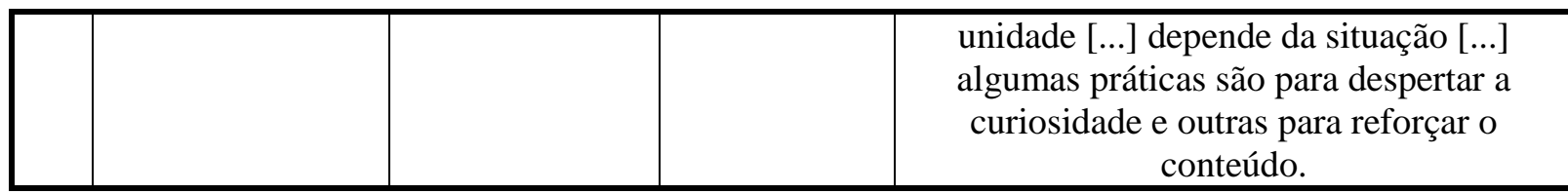

Fonte: próprias autoras, 2019.

Andrade e Viana (2017) defendem que o sucesso das atividades experimentais está diretamente atrelado a eficácia na elaboração de um planejamento, que se concentra principalmente nos objetivos propostos, considerando as ideias prévias dos estudantes a respeito da situação estudada e habilidades requeridas. Nesse sentido, é importante refletir sobre o formato de planejamento descrito pelos sujeitos dessa pesquisa, quanto a sua intencionalidade, pois mesmo que se acompanhe o roteiro dos livros didáticos de ciências não dispensa a ação de um planejamento mais elaborado, tanto dos conteúdos a serem trabalhados quanto das práticas experimentais. Além disso, embora o planejamento anual seja considerado essencial para orientação das ações pedagógicas, deve-se ter o cuidado para que o mesmo não se caracterize somente como cumprimento burocrático, desconsiderando assim, as reais necessidades de aprendizagens dos alunos. Em relação ao modo como essas atividades são propostas e executadas, Suart e Marcondes (2008) ressaltam que o mais importante é que sejam considerados os aspectos construtivistas da experimentação, a partir do grau de problematização da mesma.

\subsubsection{ENTRAVES DE APLICAÇÕES DE AULAS EXPERIMENTAIS}

O reconhecimento de que a experimentação é primordial para o processo de ensino e aprendizagem é usualmente compartilhada entre os professores. No entanto, o que se observa em diversas pesquisas é que o ensino de Ciências continua sendo pautado na mera transmissão simplista de conteúdos prontos e acabados, ou seja, conduzido de forma desinteressante e pouco compreensível, além de ser auxiliado unicamente pelo livro didático que ainda é o principal, se não o único instrumento usado pelos professores em sala de aula (GUIMARÃES, 2009; PEREIRA, 2010; BASSOLI, 2014; SILVA, 2019). Desse modo, buscou-se identificar na concepção dos professores os principais entraves de aplicações das práticas experimentais no ensino de ciências, e as categorias suscitadas foram: i) contexto didático; ii) infraestrutura e iii) carga-horária. Essas descrições com suas respectivas unidades de significados podem ser visualizadas no Quadro 3. 
Quadro 3 - Descrição das unidades de significados do Bloco III

\begin{tabular}{|c|c|c|c|c|}
\hline \multirow{8}{*}{ 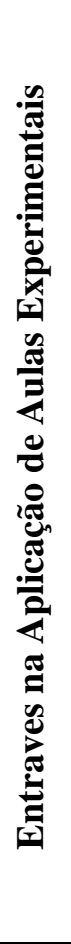 } & Categorias & $\begin{array}{l}\text { Unidades de } \\
\text { Significados }\end{array}$ & Frequência & Citações \\
\hline & \multirow{3}{*}{$\begin{array}{l}\text { Contexto } \\
\text { didático }\end{array}$} & $\begin{array}{c}\text { Rigidez de } \\
\text { cumprimento do } \\
\text { Currículo } \\
\end{array}$ & $44,0 \%$ & \multirow{3}{*}{$\begin{array}{c}\text { P3 “A gente tem que dar conta do } \\
\text { conteúdo... um dia de aula prática atrasa } \\
\text { tudo" } \\
\text { P4 "A maior dificuldade é }[. . .] \text { também por } \\
\text { conta da série que trabalho, } 6^{\circ} \text { ao } 8^{\circ} \\
\text { ano...os exemplos de experimentos dos } \\
\text { livros são complicados para os alunos" }\end{array}$} \\
\hline & & $\begin{array}{l}\text { Quantidade de } \\
\text { alunos }\end{array}$ & $23,2 \%$ & \\
\hline & & $\begin{array}{l}\text { Limitações } \\
\text { cognitivas }\end{array}$ & $38,5 \%$ & \\
\hline & \multirow[b]{2}{*}{ Infraestrutura } & $\begin{array}{l}\text { Espaços } \\
\text { inexistentes }\end{array}$ & $69,2 \%$ & \multirow{2}{*}{$\begin{array}{c}\text { P1 “[...] falta materiais: vidraria, } \\
\text { substâncias para fazer reações, } \\
\text { instrumentos }[. . .] \text { "a gente" tem que } \\
\text { improvisar[...]" } \\
\text { P2 “ [...] Existe uma deficiência muito } \\
\text { grande por não existir materiais adequados } \\
\text { para [...] realizar experimentos }[\ldots] \text { ”. }\end{array}$} \\
\hline & & $\begin{array}{l}\text { Materiais } \\
\text { inexistentes }\end{array}$ & $58,3 \%$ & \\
\hline & \multirow{2}{*}{ Carga-horária } & Reduzida & $15,4 \%$ & \multirow{2}{*}{$\begin{array}{l}\text { P9 “[...] o tempo é muito corrido }[\ldots] \text { é } \\
\text { preciso organizar horário específico com } \\
\text { horário da teoria, horário de cada turma, } \\
\text { muito complicado [...]." }\end{array}$} \\
\hline & & Inexistente & $7,7 \%$ & \\
\hline
\end{tabular}

Fonte: próprias autoras, 2019.

As três categorias suscitadas neste bloco de discussão remetem entraves profissionais relacionados a realidade ao contexto do chão da escola. Dessa forma, chama-se atenção para a presença dos signos mais recorrentes no discurso dos professores que fazem referência a "ausência de um espaço específico ou de laboratório" (69,2\%), seguida da "falta de materiais inerentes a experimentação" (58,3\%). Nessa linha de discussão, Borges (2004) afirma ser um equívoco confundir atividades práticas experimentais escolares com a necessidade de um ambiente com equipamentos especiais para a realização, uma vez elas que podem ser desenvolvidas em qualquer espaço, sem a necessidade de instrumentos ou aparelhos sofisticados. Ressalta-se que a literatura especializada comenta que experimentos simples podem ser realizados até mesmo em sala de aula, sem o aparato de equipamentos sofisticados, enfatizando que até mesmo a observação pode constituir-se parte integrante do processo de ensino e aprendizagem, desde que tenha o espaço garantido para a reflexão, desenvolvimento e construção de ideias, contribuindo assim para descobertas significativas. Nesse sentido, os materiais alternativos podem ser usados na própria sala de aula e apresentam-se como uma forma interessante de superação desses desafios (BRASIL, 2017; MACIEL; LIMA, 2011).

Em relação à "limitação cognitiva" dada por série dos alunos $(38,5 \%)$ referida como inquietação de alguns professores e que resulta em obstáculo para execução de práticas experimentais sugeridas nos livros, nos remete às discussões sobre as diferentes concepções 
epistemológicas de aprendizagem que professores carregam discutidas por diversos autores, onde esses percebem que ainda existe uma acentuada visão de que a compreensão da ciência pode ser distante daqueles que ainda são muito jovens ou que não tem currículo avançado em conhecimento de conceitos e teorias. Essa visão, considerada pela literatura como empirista, resume-se em defender que a aquisição do conhecimento científico caminha num "sentido cumulativo, ou seja, as etapas de aprendizagem se evoluem quando novos conceitos e/ou teorias se agregam aos antigos e os suplantam num movimento de superação. Ressalta-se que existem várias críticas em relação a essa visão, buscando aprofundar olhar para as relações entre o sujeito que ensina e o que aprende e o meio em que vivem, como forma crucial para a construção e apropriação de saberes significativos (GIORDAN, 1999, GONÇALVES; GALIAZZI, 2004; GOLÇALVES, 2006; TAHA, 2016, SILVA, 2019.)

Outro ponto que nos chamou atenção se direcionou a entender a pressão sofrida pelos professores quanto ao cumprimento do conteúdo planejado para o ano letivo dentro da cargahorária específica para a disciplina de ciências, que dificulta a inserção de aulas experimentais nos planejamentos dos professores. Entretanto, entende-se que apesar desses fatores se apresentarem como aspectos limitantes, a aplicação de atividades práticas mesmo que em quantidades reduzidas, desde que sejam abordadas de maneira interessante e desafiadora, já é capaz de favorecer um maior contato com a prática científica, tornando possível a identificação de questões de investigação, organização e interpretação de dados (TRIVELATO; SILVA, 2011).

As práticas experimentais são muito importantes para o processo de construção do conhecimento científico, e por isso, independentemente dos entraves de aplicações comuns nas instituições de ensino, não devem deixar de ser realizadas. Defende-se que o sentimento que deve ser estimulado é desenvolver competências nos professores e políticas de ações educacionais que, no mínimo, tenham o intuito de superar esses empecilhos e levem a efetiva elaboração de um planejamento adequado, que inclua o uso de materiais destinados para esse fim ou de materiais alternativos, que possibilitem o desenvolvimento dos experimentos significativos no tempo disponível de aula.

\section{CONSIDERaÇões FINAIS}

Considerando os resultados obtidos nessa pesquisa, foi possível perceber que as aulas práticas experimentais são consideradas pelos professores de ciência de grande importância para o processo de construção de conhecimento científico dos alunos. Entretanto, apesar da 
retórica evidenciando benefícios da experimentação e a necessidade de introduzi-las no ensino de ciências, os dados obtidos mostram que não é realidade presente na prática docente, principalmente por conta das dificuldades estruturais que acabam limitando ou interferindo no planejamento e na implementação delas. Esses obstáculos são comumente relatados em várias pesquisas em todas as partes do panorama nacional.

Desse modo, os resultados confirmaram que as escolas não estão preparadas para proporcionar um ambiente favorável ao desenvolvimento da educação científica através da experimentação. Mas por outro lado, defende-se que as dificuldades não podem ser usadas como justificativa para se deixar de lado a experimentação no ensino de ciências, uma vez que ela pode levar a uma melhoria da formação científica e de uma aprendizagem significativa. Entende-se que uma das medidas para superação ou amenização dessa problemática está na viabilização de práticas simples e que podem ser feitas com materiais alternativos.

A carência ou a inexistência de práticas nas aulas de ciências torna os alunos meros sujeitos receptores de informações, dificultando, portanto, o desenvolvimento do pensamento crítico daquilo que lhes é ensinado, e ao mesmo tempo os distanciando dos processos da ação de construção da ciência. Por outro lado, defende-se que a escola, a gestão administrativa/ pedagógica e os professores, por terem responsabilidade sobre a aprendizagem de seus alunos, devem procurar medidas para motivar a aprendizagem dos mesmos e não se acomodar com os entraves que dificultam a implementação dessas atividades. Para tanto, conforme salienta Silva (2019) é preciso que haja uma mudança de atitude por parte do poder público, quanto a fatores como: melhoria de infraestrutura, incentivos financeiros, gestão de tempo e condições para adoção de metodologias dinâmicas que auxiliem na educação científica, que, por sua alta complexidade e de suas peculiaridades, não pode ser ministrada sem a utilização de atividades práticas ou experimentos.

Outro ponto que merece ser destacado é a necessidade de uma formação inicial e continuada de forma crítica e qualificada que permita aos professores refletirem melhor a respeito do papel da experimentação no ensino de Ciências, no que concerne ao enriquecimento do processo educativo e com isso, atualizarem constantemente suas formas de trabalharem, a partir de uma qualificação sólida e abrangente e assim sentirem-se preparados e motivados para buscarem e proporem alternativas que viabilizarem a realização de atividades experimentais com mais frequência em todas as séries de ensino fundamental, superando, portanto, os obstáculos encontrados nas escolas e enraizando a concepção de que a experimentação é essencial em todas as etapas de formação do estudante. 


\section{REFERÊNCIAS}

ANDRADE, Marcelo Leandro Feitosa; MASSABNI, Vânia Galindo. O desenvolvimento de atividades práticas na escola: um desafio para os professores de ciências. Revista Ciências e Educação, v.17 n. 4, 2011.

ANDRADE, Rosivânia da Silva; VIANA, Kilma da Silva Lima. Atividades experimentais no ensino da química: distanciamentos e aproximações da avaliação de quarta geração. Ciência \& Educação, Bauru, v. 23, n. 2, p. 507-522, 2017.

ATAIDE, Maria Cristina Eloi Silva; SILVA, Boniek Venceslau da Cruz. As Metodologias do Ensino de Ciência: Contribuição da Experimentação e da História e Filosofia da Ciência.

Revista Holos, v. 27, n.4, p. 171-181, 2011.

BARDIN, Laurence. Análise de conteúdo. Lisboa: Edições 70, 2002.

BASSOLI, Fernanda. Atividade práticas e o ensino-aprendizagem de ciência (s): mitos, tendências e distorções. Revista Ciências e Educação, v. 20, n. 3, p. 579-593, 2014.

BORGES, A.Tarcísio. Novos rumos para o laboratório escolar de ciências. Caderno Brasileiro de Ensino de Física, v. 19, n.3: p.291-313, 2002.

BRASIL. Base Nacional Comum Curricular (BNCC). Brasília: MEC. 2017. Disponível em: http://basenacionalcomum.mec.gov.br/. Acesso em: novembro de 2019.

BRASIL. Lei no 9.394/96 de Diretrizes e Bases da Educação Nacional. Brasília, 20 de dezembro de 1996. Disponível em: http://portal.mec.gov.br/. Acesso em setembro de 2019.

BRASIL. Parâmetros Curriculares Nacionais: Ciências Naturais/Secretaria de Educação Fundamental. Brasília: MEC/SEF, 1998. Disponível em: http://portal.mec.gov.br/. Acesso em janeiro de 2019.

CACHAPUZ, Antonio. et al. A necessária (re)novação no Ensino de ciências. 2ed. São Paulo: Cortez, 2011.

CARNEIRO, Cleidson Carneiro. Experimentação no Ensino de Química: Caminhos e Descaminhos Rumo à Aprendizagem Significativa. Revista Química Nova na Escola, v. 31 n. 3, 2009.

CARVALHO, Ana Maria Pessoa de; PÉREZ, Daniel Gil. Formação de professores de ciências. 8ed. São Paulo: Cortez, 2006.

COLL, César. Aprendizagem escolar e construção do conhecimento. Porto Alegre: Artes Médicas, 1994.

DELIZOICOV, Demétrio; ANGOTTI, José André. Metodologia do Ensino de Ciências. São Paulo: Cortez, 2000.

FERRARO, José Luis Schifino. Currículo, experimento e experiência: contribuições da Educação em Ciências. Educação (Porto Alegre), v. 40, n. 1, p. 106-114, 2017. 
GALIAZZI, Maria do Carmo; GONÇALVES, Fábio Peres. A natureza pedagógica da experimentação: uma pesquisa na licenciatura em química. Revista Química Nova. vol.27 no.2 São Paulo, 2004.

GIORDAN, Marcelo. O papel da experimentação no ensino de Ciências. Revista Química Nova na Escola, v.10, 1999.

GONÇALVES, Fabio Peres; GALIAZZI, Maria do Carmo. A natureza das atividades experimentais no ensino de ciências: um programa de pesquisa educativa nos cursos de Licenciatura. In: MORAES, Roque; MANCUSO, Ronaldo (org). Educação em ciências: Produção de currículos e formação de professores. Ijuí: Unijuí, 2004.

GONÇALVES, Fábio Peres; MARQUES, Carlos Alberto. Contribuições pedagógicas e epistemológicas em textos de experimentação no ensino de química. Revista Investigações em Ensino de Ciências, vol. 11, n. 2, 2006.

GUIMARÃES, Cleidson Carneiro. Experimentação no ensino de química: caminhos e descaminhos rumo à aprendizagem significativa. Revista Química Nova na Escola, vol. 31, n. 3, 2009.

INEP. Instituto Nacional de Estudos e Pesquisas Educacionais Anísio Teixeira. Nota Técnica: Índice de Desenvolvimento da Educação Básica - IDEB (2017). Brasília/DF:MEC.

Disponível em: http://www.inep.gov.br/download/Ideb. Acesso em: 18 de novembro de 2019.

JÚNIOR, Edvargue Amaro da Silva; PARREIRA, Gisele G. Reflexões sobre a importância da experimentação no ensino da Química no ensino médio. Revista Tecnia, v.1, n.1, 2016.

LÜDKE, Menga; ANDRÉ, Marli Eliza Dalmazo Afonso de. Pesquisa em educação: abordagens Qualitativas. 2a ed. São Paulo: EPU, 2015.

MACIEL, Adeilton Pereira; LIMA, Joacy Batista. Alternativas para o Ensino de Química na educação básica: A experiência no cotidiano da docência em química. São Luís: EDUFMA, 2011.

MARQUES, Clara Virgínia Vieira Carvalho Oliveira. Perfil dos Cursos de Formação de Professores dos Programas de Licenciatura em Química das Instituições Públicas de Ensino Superior da Região Nordeste do Brasil. 2010. 291flhs. Tese (Doutorado) -Universidade Federal de São Carlos, São Carlos, São Paulo, 2010.

PEREIRA, Boscoli Barbosa. Experimentação no ensino de ciências e o papel do professor na construção do conhecimento. Cadernos da FUCAMP, vol. 9, n. 11, 2010.

PINTO, Luizelio Veloso. Concepções de Professores de Química sobre proposições de Atividades Experimentais na direção da Alfabetização Científica. 2018.101f. Dissertação (Mestrado em Ensino de Ciências e Matemática) - Universidade Federal do Maranhão, São Luís, Maranhão, 2018.

PRSYBYCIEM, Moisés Marques.; SILVEIRA, Rosimari Monteiro Castilho Foggiatto; SAUER, Elenise. Experimentação investigativa no ensino de química em um enfoque CTS a 
partir de um tema sociocientífico no ensino médio. Revista Electrónica de Enseñanza de las Ciencias, v. 17, n. 3, 602-625, 2018.

POZO, Juan Ignácio. Aprendizes e mestres. Porto Alegre: Artmed, 2002

RAMOS, Luciana Bandeira da Costa; ROSA, Paulo Ricardo da Silva. O Ensino de Ciências: Fatores Intrínsecos e Extrínsecos que Limitam a Realização de Atividades Experimentais pelo Professor dos Anos Iniciais do Ensino Fundamental. Revista Investigações em Ensino de Ciências, v. 13, n. 3, 2008.

ROSITO, Berenice. A. O ensino de ciências e a experimentação. In: MORAES, Roque. e or. Construtivismo e ensino de ciências reflexões epistemológicas e metodológicas. $2^{\mathrm{a}} \mathrm{ed}$. Porto Alegre: EDIPUCRS. 2003.

SANTOS, Paulo Roberto dos. O ensino de Ciências e a ideia de cidadania. Revista Mirandum, vol. 17, 2006.

SICCA, Natalina Aparecida Laguna. Razões históricas para uma nova concepção de laboratório no ensino médio de química. Paidéia, FFCLRP-USP, Ribeirão Preto, 1996.

SILVA, Thanielle Souza. Experimentação no Ensino de Química e Avaliação da Aprendizagem: o enredo da prática docente em foco. 2019. 103 f. Dissertação (Mestrado em Ensino de Ciências e Matemática) - Universidade Federal do Maranhão, São Luís, Maranhão, 2019.

SILVA, Lenice Heloisa de Arruda; ZANON, Lenir Basso. Experimentação no ensino de ciências. In: SCHNETZER, Roseli Pacheco.; ARAGÃO, Rosália Maria Ribeiro (Orgs.) Ensino de Ciências: fundamentos e abordagens. Campinas: V Gráfica, 2000. p. 120-153.

SILVA, Cleberson Souza; CLEMENTE, Alan Dumont; PIRES, Diego Arantes Teixeira. Uso da experimentação no ensino de química como metodologia facilitadora do processo de ensinar e aprender. Revista CTS IFG Luziânia, v. 1, n. 1, 2015.

STRAUSS, Anselm L.; CORBIN, Juliet M. Pesquisa qualitativa: técnicas e procedimentos para o desenvolvimento de teoria fundamentada. 2 ed. Porto Alegre: Artmed, 2008.

SUART, Rita de Cássia.; MARCONDES, Maria Eunice Ribeiro. As habilidades cognitivas manifestadas por alunos do ensino médio de química em uma atividade experimental investigativa. Revista Brasileira de Pesquisa em Educação em Ciências, v. 8, 2008.

TAHA, Marli Spat, LOPES, Cátia Silene Carrazoni, SOARES, Emerson de Lima, FOLMER, Vanderlei. Experimentação como ferramenta pedagógica para o ensino de Ciências. Revista Experiências em Ensino de Ciências, v.11, n. 1, 2016.

TRIVELATO, Silvia Frateschi; SILVA, Rosana Louro Ferreira. Atividade lúdica e ensino de ciências - a biodiversidade como exemplo. In: TRIVELATO, Silvia Frateschi; SILVA, Rosana Louro Ferreira. Ensino de Ciências. São Paulo: Cengage Learning. 2011. (Coleção ideias em ação).

Recebido em: 14 de janeiro de 2020.

Aprovado em: 15 de abril de 2020. 